DOI: $10.6060 / \mathrm{mhc} 190864$ s

\title{
Recent Advances in 2D Polymeric Phthalocyanines: Synthesis, Characterization, Applications and New Challenges
}

\author{
Vitaly I. Korepanov and Daria M. Sedlovets ${ }^{\circledR}$ \\ Institute of Microelectronics Technology and High Purity Materials RAS, 142432 Chernogolovka, Russia \\ ${ }^{\circledR}$ Corresponding authorE-mail: sedlovets@iptm.ru
}

This article is dedicated to Prof. Dieter Wöhrle, whose works for a long time have been the highest standard and a source of inspiration for us

\begin{abstract}
$2 D$ polyphthalocyanines (PPCS) are actively studied as advanced materials for new generation energy and microelectronics. Some time ago such compounds were dubbed "just a dream of synthetic chemists", what was a perfect reflection of, on the one hand, high promise, and, on the other hand, experimental difficulties faced with the 2D polymers. Despite a long history of PPCs (since late 1950s), it was shown recently that in many works the reaction products were mis-interpreted, and the studied compounds should be assigned to a low degree of the polymerization. Recent years, the discovery of graphene has inspired a new wave of interest to PPCs. From the graphene point of view, the questions are: whether we can make other graphene-like materials with modified properties? Can we use metal atoms to tune its electronic properties? Can we make a magnetic 2D material? From the polymer chemistry point of view, the major problem is why the common synthetic approaches and characterization techniques didn't work for this polymer as expected? And how to identify the reaction products? This review covers evolution of the synthetic approaches, establishment of the reliable characterization techniques, as well as the promising applications of $2 D$ PPCs and the "new dreams" in science and technology of these materials.
\end{abstract}

Keywords: Polyphthalocyanines, 2D polymers, spintronics, catalysis, spectroscopy.

\section{Последние Аостижения по Авумерным полифталоцианинам: синтез, характеризация, приложения и новые вызовы}

\author{
В. И. Корепанов, А. М. Седловец ${ }^{@}$
}

Институт проблем технологии микроэлектроники и особочистых материалов РАН, 142432 Черноголовка, Россия ${ }^{\circledR}$ E-mail: sedlovets@iptm.ru

\begin{abstract}
Двумерные полифталоцианины (ПФЦ) активно изучаются как перспективные материаль для энергетики и микроэлектроники нового поколения. Недавно эти полимеры были названы «всего лишь мечтой химикасинтетика», что отлично отражало, с одной сторонь, высокую привлекательность, а с другой сторонь, экспериментальные трудности в работе с двумерными полимерами. Несмотря на долгую историю ПФЦ(с конца 1950x), недавно было показано что во многих работах были неправильно интерпретированы продукты реакции, и изучавшиеся соединения следовало отнести к низкой степени полимеризации. Недавнее открытие графена вызвало новую волну интереса к ПФЦ. Подходя со стороны графена, можно спросить, можно ли получить графеноподобный материал с модифицированными свойствами? Можно ли при помощи атомов металла «настраивать» электронные свойства? Можно ли сделать магнитный двумерный материал? С точки зрения химии полимеров, основной вопрос - почему общепринятые подходы к синтезу и характеризации не сработали для ПФЦ? Как правильно идентифицировать продукты реакции? В этом обзоре описана эволюция подходов к синтезу, установление надёжных методов характеризации, а также перспективные применения и «новые мечтыр в науке и технологии этих материалов. Эта статья посвящена проф. Дитеру Вёрле, чьи работы были для нас высоким стандартом и источником вдохновения в течение долгого времени.
\end{abstract}

Ключевые слова: Полифталоцианины, двумерные полимеры, спинтроника, катализ, спектроскопия. 


\section{Introduction}

Despite its name, "polyphthalocyanine" (PPC) is in fact not a polymer of phthalocyanine. In the polymer, benzene rings are shared by the adjacent phthalocyanine units, therefore, unlike $\mathrm{PC}$ with four benzene rings per molecule, PPCs technically have only two benzene rings per unit cell ${ }^{[1]}$ (Figure 1). The term "polyphthalocyanine" was introduced by Winslow and Antonelli in 1957 [2] and is conventionally used since then for these polymers, but it is important to understand that the "monomeric unit" of PPC is not the phthalocyanine. The direct consequence of this fact is that spectroscopic signatures of PPC should not correspond to those of PC. ${ }^{[3]}$

The structure of PPCs resembles patterned graphene: it is a 2D conjugated sheet, with metal atoms (or $\mathrm{H}_{2}{ }^{2+}$ ) incorporated at $\sim 1 \mathrm{~nm}$ distance in a square-like order (Figure 1). Unlike graphene, the symmetry of a single layer is not hexagonal, but rather $\mathrm{D}_{4 \mathrm{~h}}$. This unique structure makes 2D PPC highly promising material for a wide variety of technological applications, including catalysis, ${ }^{[4]}$ memristors, ${ }^{[5]}$ magnetic storage devices, ${ }^{[6]}$ spintronics, ${ }^{[7]}$ advanced fuel cells, ${ }^{[8]}$ optoelectronics $^{[9]}$ and others. A natural question to ask is why these materials are not widely used yet? The main problem of working with PPCs is their exceptionally difficult processability. PPCs cannot be handled by the conventional processing techniques like spin-coating, vacuum evaporation and other approaches based on dissolution, melting or evaporation. ${ }^{[10]}$ Unlike linear polymers, the products of 2D polymerization are insoluble and do not melt without decomposition. The properties of the material also can vary with the synthetic conditions. ${ }^{[1]}$ These factors also make the characterization of the 2D polymers rather difficult. ${ }^{[12]}$ For industrial applications however, the desired product should be obtained in a required morphology (typically as a thin film), should be well characterized, and the production should be well documented and based on the widely available experimental equipment. In a review of Schlüter et al.. ${ }^{[13]} 2 \mathrm{D}$ polymers were dubbed "just a dream of synthetic chemists", which well reflects the current state of the problem by 2009 .

The history of 2D PPCs started late 1950s,,$[2,12,14]$ and the obtained material can be described as a poorly characterized dark solid, practically un-processable and more or less useless for technology. After the influential series of works made by Prof. Wöhrle in $1970-80 \mathrm{~s}^{[15]}$ (to cite just a few), the products of 2D polymerization became more or less characterized and highly important information on the conditions and products of the synthesis has been accumulated. The problem of processability however has not been solved by that time.

The discovery of technological properties of graphene in 2000s has inspired a new wave of interest to 2D polymers. Unlike graphene, PPCs can have finite band gap, and electronic properties of the material can vary with changing the incorporated metal. One more highly promising feature of PPCs coming from the metal is the ability to tune spin-related properties of the polymer. This can be a unique advantage of such materials for applications in magnetic devices and spintronics. ${ }^{[7]}$ PPCs have been experimentally tested for some practical applications, ${ }^{[4-5,16]}$ and the progress with the processability has been achieved. ${ }^{[10 a, 11,17]}$

Recently, it was also shown that the 2D PPC material obtained in different works has strongly different spectra (IR, Raman, UV-Vis). ${ }^{[3]}$ This fact was interpreted with the help of the quantum-chemical calculations and it was found that the product assigned in many works to 2D PPCs does not have the $2 \mathrm{D}$ conjugated structure, but instead contains an intermediate product (octacyanophthalocyanine, OCP) as a major component. We may say that for many works, 2D PPCs were not "a dream", but rather "an illusion" of synthetic chemists until the reliable characterization has been established.

In the first section of this review, we describe different synthetic approaches to PPCs. Next, we address the characterization of 2D PPCs and interpretation of the reaction products and the reasons why the common characterization approaches failed with these materials. In the third section we list main applications of PPCs. In the end, we describe current challenges and problems (new "dreams") in the science and technology related to PPCs.

\section{Chemical Approaches to 2D PPCs}

\subsection{Early works}

In the pioneering works, few chemical reactions have been tested for the PPC synthesis. The key precursor

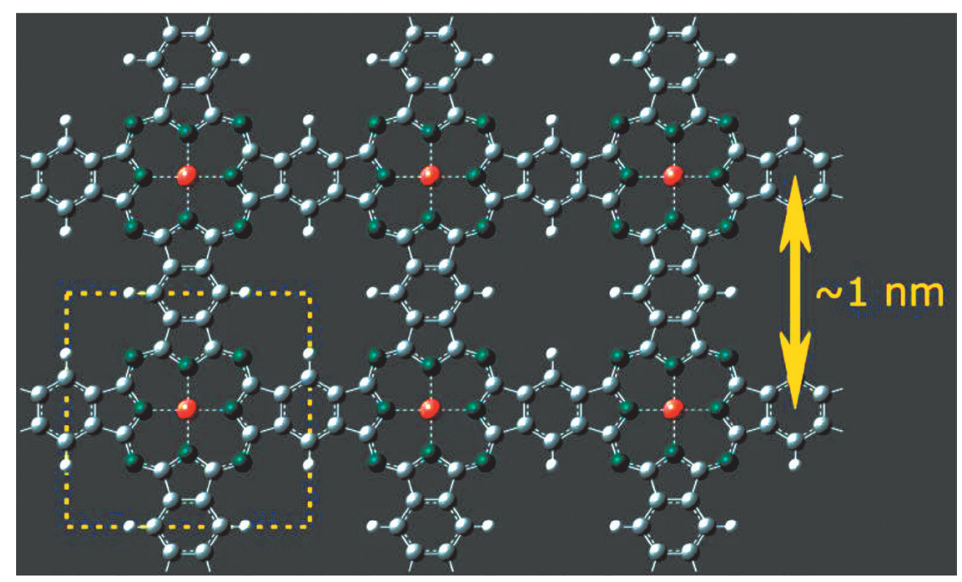

Figure 1. Chemical structure of PPCs. Metal atoms are shown in red, unit cell are highlighted with yellow square. 
was either pyromellitic dianhydride (or the corresponding acid ${ }^{[12,14 b]}$ (Figure 2) or pyromellitic tetranitrile (PMTN) (Figure 3). In the first case, urea was used as one of reagents. Metal was taken in a form of salts (typically chloride ${ }^{[14 a]}$ ). It was found however that oxygen-containing reagents result in oxygen-containing groups in polymer structure and low polymerization degree. ${ }^{[14 \mathrm{~b}]}$

Despite that the reaction of pyromellitic dianhydride with metal salts and urea has spread, ${ }^{[8,18]}$ in the main route to PPC synthesis is polycyclomerization of PMTN (Figure 3). This approach is widespread due to that the PC molecule contains 4 benzene rings with an equivalent arrangement and the same reactivity. Thus, the combination of phthalocyanine components through terminal benzene rings ideally leads to the formation of a polymer structure. Several highly influential works on this approach were reported by Wöhrle et al. ${ }^{[10 \mathrm{~b}, 15 \mathrm{~b}, 15 \mathrm{~d}, 19]}$

The reaction of PMTN with anhydrous $\mathrm{CuCl}_{2}$ was studied in the work. ${ }^{[15 \mathrm{~d}]}$ The powder mixture was placed in a glass ampoule, which was triple evacuated, filled with dry argon, and then sealed and heated at $400{ }^{\circ} \mathrm{C}$ for 4 hours. Obtained powder was purified from low molecular weight fractions in a Soxhlet apparatus. From IR and UV-Vis spectra the authors concluded that structurally homogeneous polymers are obtained only when using copper as a coordinating metal, while use of $\mathrm{Mg}, \mathrm{Al}, \mathrm{V}, \mathrm{Cr}, \mathrm{Mn}, \mathrm{Fe}$, $\mathrm{Co}, \mathrm{Ni}, \mathrm{Zn}$ salts leads to irregular structure formation.
The use of lithium as a coordinating metal with following replacement by zinc was studied in. ${ }^{[19]}$ To obtain PPC, a suspension of PMTN in distilled and dehydrated 1-pentanol was prepared, and then it was mixed with lithium metal powder, and kept during two weeks. The product was heated at $100{ }^{\circ} \mathrm{C}$ for 24 hours in DMF with an excess of $\mathrm{ZnOAc}$. Alcoholate ions started a chain reaction of tetramer formation due to a nucleophilic attack on nitrile groups. To obtain a PPC coating on $\mathrm{SiO}_{2}$ particles, quartz powder was mixed with $\mathrm{Co}_{2}(\mathrm{CO})_{8}$, and then mixture was sealed in ampoule with PMTN and heated. This method required an excess of PMTN to exclude unreacted metal remaining on the carrier particle surface. The remaining PMTN can be removed after synthesis by washing in acetone.

In the work $^{[20]}$ the reaction of PMTN with copper powder was studied. FTIR spectra showed pronounced band from terminal groups $\left(\mathrm{C} \equiv \mathrm{N}\right.$ at $\left.2230 \mathrm{~cm}^{-1}\right)$. A good crystallinity of the obtained product was confirmed using XRD.

\subsection{Attempts to synthesize thin films of PPC}

To obtain thin films of the polymers has been a challenge for a long time. An interesting work has been reported in 1987 by Wöhrle and co-workers, who first visualized a crystal structure of free-standing polymer film with TEM. ${ }^{[15 b]}$

An important aspect of the polymerization of tetranitrile (Figure 3) is the reactivity of cyano groups. Once
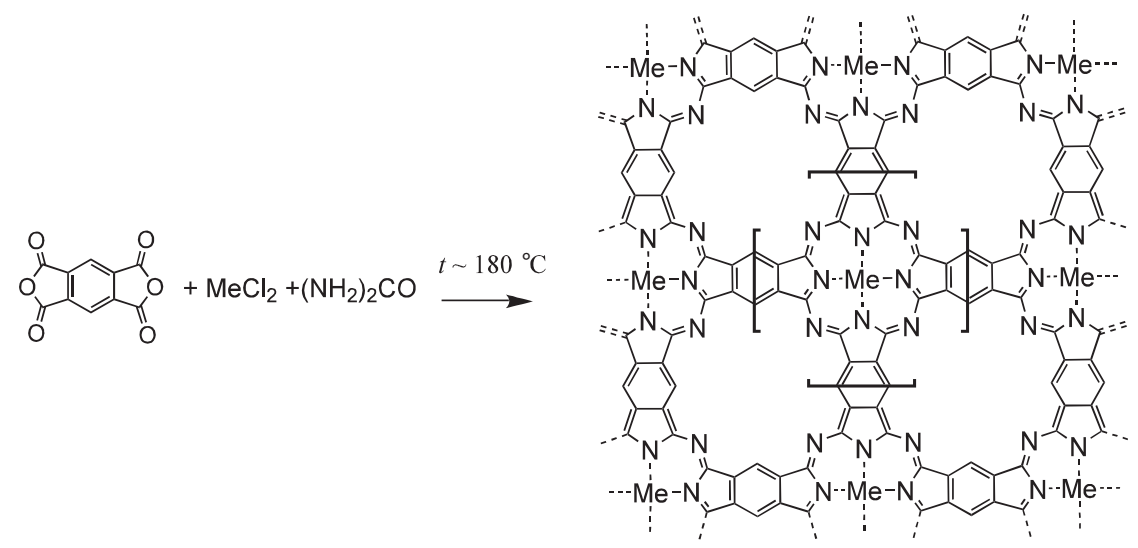

Figure 2. One of the reactions tested for the synthesis of PPCs in early works. ${ }^{[12,14 b]}$
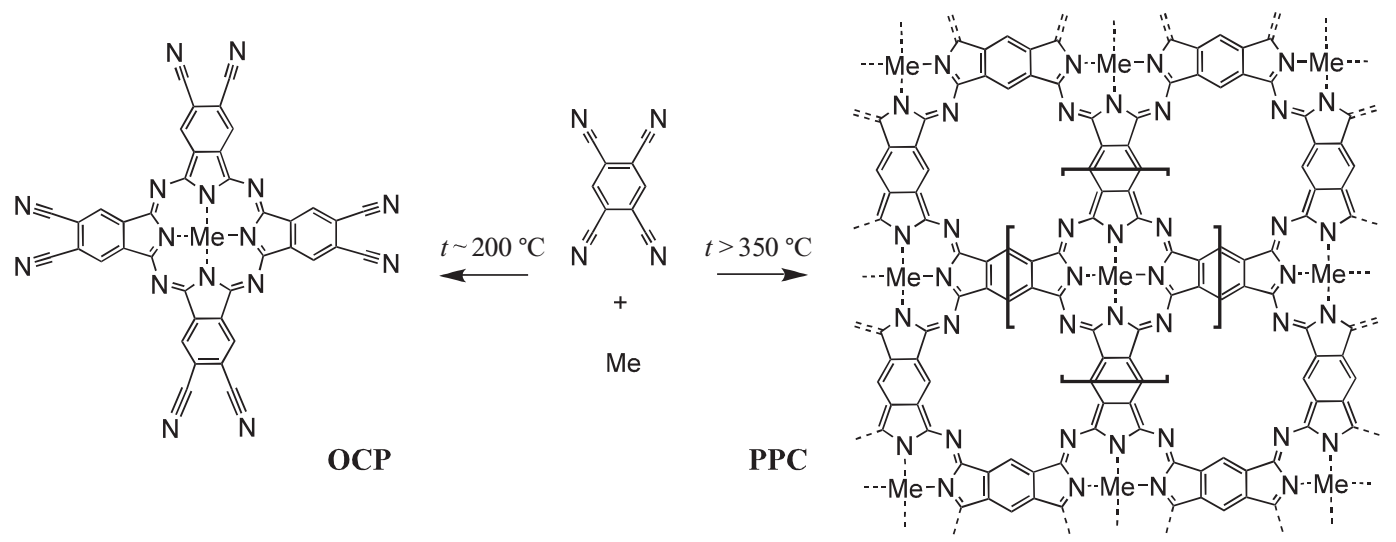

Figure 3. Most common synthetic route to PPCs. Depending on temperature and chemical set-up, this reaction can result in different products. ${ }^{[11,22]}$ The low-molecular-weight product with OCP (left) as a major component was in some works ${ }^{[4 a]}$ confused with the $2 \mathrm{D}$ polymer (right). 
the first PC ring is formed, the reactivity of the remaining cyano groups for PC formation reaction is lowered, since electron-withdrawing two cyano groups are already used. Activation energy required to continue the polymerization is higher than that for the first step. As a result, while the first ring can form below $200{ }^{\circ} \mathrm{C}$, the optimal temperature for the polymerization is $420^{\circ} \mathrm{C} .^{[21]}$

It was demonstrated that the reaction of PMTN vapour with a copper film at a temperature below $350{ }^{\circ} \mathrm{C}$ result in an OCP formation, while at a temperature above $350{ }^{\circ} \mathrm{C}$ the $2 \mathrm{D}$ polymer is formed (Figure 3). In recent years, this hypothesis has been confirmed using tunnelling microscopy ${ }^{[22]}$ and various spectroscopic techniques. ${ }^{[3]}$

Later, the same group ${ }^{[10 b]}$ deposited thin copper layers $(1.5-30 \mathrm{~nm})$ on glass or quartz substrates by radio frequency sputtering, then substrates were placed in a glass ampoule containing an excess of PMTN and were rapidly evacuated. The reaction (Figure 3) was carried out in a sealed ampoule at $400{ }^{\circ} \mathrm{C}$ for different times (4-24 hours). When a copper layer thickness was $9.8 \mathrm{~nm}$, the thickness of the polymer was $228 \mathrm{~nm}$. After the formation of the first few polymer layers, $\mathrm{Cu}$ atoms diffuse through the polymer film to react with the PMTN vapors. Four PMTN molecules react with each other with the formation of octacyanophthalocyanine (OCP) and subsequent conversion to a polymer.

Abe and co-workers ${ }^{[23]}$ obtained 200-nm films of metalfree PPC using an evaporation-polymerization process. PMTN was placed in the reactor at a distance of $2.5 \mathrm{~cm}$ from the glass substrate. The reactor was evacuated to $200 \mathrm{~Pa}$, and heated to $320{ }^{\circ} \mathrm{C}$ for 8 hours. $\mathrm{H}_{2}$ PPC films were characterized by IR spectrometry and SEM. Then polymers were successfully tested as active layers in rectifying devices.

In the work ${ }^{[24]}$ the polymerization of copper PC was carried out in a glow discharge plasma under reduced pressure $(13 \mathrm{~Pa})$. CuPC was evaporated at a temperature of $350-450{ }^{\circ} \mathrm{C}$ using W filament in plasma setup. A substrate was placed on the electrode, and plasma was generated for 60 seconds. During this time, the monomer completely evaporated, and the substrate became covered with a smooth continuous polymer film (60-300 nm). The authors reported only indirect evidence of a high degree of polymerization the films obtained did not dissolve either in pyridine or in concentrated sulfuric acid (good solvents for monomers). Electronic spectra indicated interaction between PC units in film. Material demonstrated a good photovoltaic response.

Yudasaka and co-workers used simultaneous evaporation of PMTN and copper in a chamber with thin nitrogen (0.01-0.1 Pa) at a temperature of $90{ }^{\circ} \mathrm{C}$ and $1100{ }^{\circ} \mathrm{C}$, respectively. ${ }^{[21]}$ As a result of sputtering, a film with a thickness of $\sim 1 \mu \mathrm{m}$ was obtained on a glass plate, which was sealed in an ampoule with nitrogen and kept at a temperature of $350{ }^{\circ} \mathrm{C}$ and $420{ }^{\circ} \mathrm{C}$ for several days. Authors attributed IR band broadening in the product spectrum to non-uniform polymerization degree of it.

Later, CuPPC films with $0.15 \mu \mathrm{m}$ thickness were grown through laser-assisted molecular beam deposition. ${ }^{[25]}$ The metallic copper in gas phase was generated through the ablating a $\mathrm{Cu}$ target. PMTN was evaporated by a pulsed beam from a U-tube under compressed He. PMTN molecular beam was mixed with the flow of $\mathrm{Cu}$ cluster at $2 \mathrm{~cm}$ distance from the substrate. The process was carried out in ultrahigh vacuum $\left(10^{-3} \mathrm{~Pa}\right)$. Therefore, the possibility of the $\mathrm{O}_{2}$ presence in the chamber is completely excluded. CuPPC was formed within the molecular beam, prior to deposition on the substrate, therefore no further heating was required. XPS showed that copper fully reacted and the film contained no neutral copper atoms $\left(\mathrm{Cu}^{0}\right)$. UV-Vis measurements indicated that film consisted of both monomeric (singlecore) and poly-CuPC.

\subsection{Single-layer PPCs}

In 2010, Abel and co-workers obtained FePPC as single-layer flakes with lateral size of $10-30 \mathrm{~nm}$ by simultaneous deposition of iron and PMTN under ultrahigh vacuum on an atomically clean surface of $\mathrm{Au}(111)$ and $\mathrm{Ag}(111) .^{[26]}$ The samples were investigated using STM, the authors concluded that this material can exhibit spin-polarized conduction. Various stoichiometric ratios were achieved by varying the time of the reagents evaporation. The control over stoichiometry was found being critical for a successful reaction: an excess of organic molecules or metal can lead formation of an indeterminate disordered phase, and only the ratio PMTN:Fe $=2: 1$ results in the desired product. The reaction occurring at a ratio of 4:1 also leads to a controlled formation of the OCP (Figure 3). This work was followed by a detailed study by STM of the processes occurring during the formation of MnPPC. ${ }^{[22]}$ In a vacuum chamber, manganese was deposited on the $\operatorname{Ag}(111)$ surface with the following PMTN evaporation at $100{ }^{\circ} \mathrm{C}$. As a result of the cooperative deposition of $\mathrm{Mn}$ atoms and organic molecules at room temperature, a two-dimensional metal-organic structure is formed with a stoichiometric ratio of components 2:1. The first reaction stage is carried out at $142{ }^{\circ} \mathrm{C}$. It results in the formation of the MnOCP, the molecules of which then self-assemble as a result of binding by hydrogen bridges and the metal-ligand interaction in the supramolecular matrix. The second stage at $342{ }^{\circ} \mathrm{C}$ leads to the formation of small domains (about $5 \mathrm{~nm}$ ) of 2D PPC with a small amount of residual manganese atoms.

\subsection{Other morphologies of PPC material in recent works}

In addition to thin films, several interesting applications were reported for other morphologies of the polymeric material.

Cobalt $^{[27]}$ and iron ${ }^{[28]}$ PPC powders can be obtained through the annealing of 4,4',4',4"',-phthalocyanine tetracarboxylic acid of $\mathrm{Co} / \mathrm{Fe}$ at $400{ }^{\circ} \mathrm{C}$ under $\mathrm{Ar}$ for 2 hours. CoPPC and FePPC were used in methanol fuel cell and magnesium air fuel cells, respectively. The materials were investigated by TGA, UV-Vis, XRD and XPS.

3D cross-linked polymeric networks can be synthesized through the solvothermal method..$^{[4 a, 16,29]}$ Materials were prepared through the polymerization of PMTN and anhydrous chloride of $\mathrm{Co}$, Fe in 2:1 stoichiometry by microwave heating in pentanol at $180{ }^{\circ} \mathrm{C}$ with the addition of a surfactant. The resulting products were extracted by centrifugation and used as catalyst in electrocatalytic $\mathrm{O}_{2}$ and $\mathrm{CO}_{2}$ reduction, as well as in flexible $\mathrm{Li}-\mathrm{CO}_{2}$ Batteries. Raman and IR spectra of such materials are close to monomer ones. 
Recently, CuPPCs were synthesized through the reaction between PMTN and copper deposited on glass. ${ }^{[30]}$ Depending on the temperature and time of synthesis, either disparate nanoclusters $\left(<350{ }^{\circ} \mathrm{C}\right)$, or nanofibers and nano-needles with a diameter of about $30 \mathrm{~nm}\left(400{ }^{\circ} \mathrm{C}\right)$ or a large globular structures $\left(>550{ }^{\circ} \mathrm{C}\right)$ were obtained. $\mathrm{UV}-\mathrm{Vis}$ and XPS spectra were used for characterization. It is expected that nanostructured poly-CuPC can be applied in photocatalysis.

\subsection{Recent works on the CVD growth of thin films}

A new synthetic approach was suggested by our group. A thin layer (few nm) of metal $\left(\mathrm{Cu}^{[10 \mathrm{a}]}\right.$ or $\left.\mathrm{Cr}, \mathrm{Ni}, \mathrm{Fe}, \mathrm{Co}^{[11]}\right)$ was deposited on a substrate and placed in a reactor for chemical vapor deposition (CVD). Therein, it was exposed to the PMTN vapor at reduced pressure for a few hours. Reactions in a CVD set-up were performed in a quartz tube reactor, placed in a two-zone oven. PMTN was evaporated in a first zone $\left(170{ }^{\circ} \mathrm{C}\right)$, while the wafers were placed in a second one $\left(420{ }^{\circ} \mathrm{C}\right)$. For $\mathrm{H}_{2} \mathrm{PPC}$, instead of metal, we used pre-coating with molybdate catalyst. ${ }^{[17]}$

This procedure was recently used by Guo's group ${ }^{[5]}$ to obtain CuPPC for non-volatile memory device. Crystallinity and high polymerization degree of the film were confirmed using TEM, XPS and UV-Vis spectra.

As discussed above, formation of a new PC core is kinetically preferred over the continued polymerization of the already-formed macromolecule. To force the polymerization to continue, it is important to reduce the concentration of the precursor. In the work ${ }^{[1]}$ it was done by slow supply of PMTN through gas phase, while the reaction proceeded at the vapor/solid interface. In contrast, if the PMTN is supplied in excess (liquid/solid interface), the low polymerization degree is observed in the resulting material at the same temperature. Thus, by controlling the concentration of the precursor, it is possible to manipulate the polymerization degree.

\subsection{Summary on synthetic approaches}

The main synthetic route to PPCs is the cyclomerization of PMTN (Figure 3). Either molybdate ions or metals (elementary/oxides/salts) are used as a catalyst or reagent, respectively. The synthesis requires inert atmosphere and elevated temperature. Bulk reactions lead to low uniformity and polymerization degree of obtained material. Mainly, quasi-two-dimensional samples were either thick films (from several hundred $\mathrm{nm}$ to microns) or individual crystallites with a grain size of the order of units or tens of microns.

From the synthesis conditions point of view, the reaction can proceed in two ways (depending on temperature): at about $200{ }^{\circ} \mathrm{C}$ the major product is OCP, while the $2 \mathrm{D}$ polymerization requires significantly higher temperatures of above $350{ }^{\circ} \mathrm{C}$. It was recently shown however that even at the optimal temperature $\left(420^{\circ} \mathrm{C}\right)$, the reaction can be performed in two different regimes: heterogeneous (vapor/solid interface) and quasi-homogeneous (liquid/solid interface). These two modes yield two kinds of polymers: ordered and cross-linked, correspondingly.

\section{Characterization of 2D PPCs}

From the very first reports, the characterization of PPCs was found to be difficult. ${ }^{[12]}$ Ideally, the desired information should include chemical composition (and therefore a proof of the chemical formula of the target material), polymerization degree (or the size of the ordered domain), layer stacking (which can be different, at least for monomeric PCs) and concentration of the defects (most important among which are the terminal groups, since this is a polymer). Why the common characterization approaches were failing for a long time with 2D PPCs? How should we characterize PPCs in a reliable and efficient way? After modern experimental and computational techniques became available, we can answer these questions.

In early works, when the bulk polymer was synthesized, the products were characterized by the elemental analysis (especially carbon-to-nitrogen ratio), as well as end-group titration. ${ }^{[14 b]}$ These methods give very limited information on the polymerization degree, and are hardly applicable to the nanoscale objects such as thin films. Infrared spectroscopy became a standard tool for PPCs since 1970s..$^{[18,31]}$ Important standard was introduced later by Wöhrle and coworkers, who suggested to compare the spectra of the polymer with those of the pre-cursors and the OCP. ${ }^{[1,15 a]}$ One more important technique widely used in their works was the UV-Visible absorption. ${ }^{[1]}$ More recently, reliable experimental data became available from $\mathrm{XRD}^{[20]}$ and XPS techniques, ${ }^{[5]}$ as well as TEM $^{[32]}$ and STM $^{[26]}$ imaging.

At this point, we should mention that the materials obtained in different works by different methods had significantly different physical characteristics. Most notably, the solubility of PPC material in available solvents (such as sulphuric acid and $N$-methylpyrrolidone) ranged from soluble ${ }^{[4 a]}$ to partially soluble ${ }^{[15 b]}$ and completely insoluble. ${ }^{[1]}$ Jumping ahead, we agree with the conclusions of Wöhrle and co-workers that the true polymers are insoluble in all organic solvents, and only the fraction with low molecular weight can be dissolved in concentrated sulphuric acid. This drastic variation in the materials obtained by different methods is observed by the characterization techniques in different ways. We will discuss them separately. Most pronounced difference was found in infrared spectra.

\subsection{Infrared spectra}

When the 2D PPC if formed from PMTN through the reaction shown in Figure 3, it is natural to look for the characteristic signatures of the phthalocyanine ring in the IR spectra. This intuitive idea was followed for a long time even in the recent works: ${ }^{[4 a]}$ formation of $2 \mathrm{D}$ PPC was often "evidenced" by observation of the PC-like bands. Surprisingly, this is the point at which a chemical intuition fails. The spectral pattern resembling monomeric PCs is an indication that the $2 \mathrm{D}$ polymer is not a major product of the reaction.

In 2013, it was reported that thin films of PPCs formed in the CVD set-up have the IR spectra significantly different from those observed before. ${ }^{[10]}$ The spectra did not resemble those of monomeric PCs, but instead showed much less number of peaks. The authors assigned 
the difference to a higher polymerization degree than that reported before. At that time this statement seemed to contradict many works published throughout the few decades. Although it was supported by UV-Vis, TEM and XRD data, the decisive arguments were reported much later, after the quantum-chemical calculations of the vibrational spectra became available. ${ }^{[3]}$

Within the series of MePPCs with different metals vibrational spectra are very close to each other. ${ }^{[3,11]}$ Same is true for monomeric PCs. ${ }^{[33]}$ Vibrational bands observed in the fingerprint region belong to the intramolecular modes of the organic skeleton. The general spectral assignment therefore is applicable to the whole series, it was therefore suggested to consider only one compound as a general model. ${ }^{[3]}$ Figure 4 shows experimental and calculated IR spectra of CuPPC compared to those of "monomeric" CuPC. Calculations for $\mathrm{CuPC}$ were done for isolated molecule (BP86 GGA functional with def2-SV(P) basis set), while for CuPPC the 3D periodic structure was taken (PBEsol functional with high-throughput ultrasoft pseudopotentials). ${ }^{[3]}$
Fewer peaks for PPC than for PC is the consequence of the fact that while the PC has 57 atoms in the molecule, the translational unit in the polymer has only 33 atoms (Figure 3). In the $\mathrm{D}_{4 \mathrm{~h}}$ point group (symmetry of $\mathrm{PC}$ molecule and of perfect sheet of 2D polymer), there are total 36 symmetry-allowed bands in the IR spectrum of the monomer as compared to 22 in that of the polymer. Not all of these bands have high intensity, and not all of them fall in the fingerprint region, which makes the IR spectrum of PPC comparatively simple. ${ }^{[3]}$

Besides the number and the position of the peaks, another important spectroscopic signature of well-polymerized PPCs is the absence of the terminal groups. If PMTN is used as a pre-cursor, these groups have triple $\mathrm{C} \equiv \mathrm{N}$ bond which gives a distinct strong signal at $2220 \mathrm{~cm}^{-1}$. Recently it was shown that, depending on a chemical set-up, it is possible to obtain either well-polymerized PPCs, or a crosslinked product, in which the conjugation is mostly limited to a single PC unit. These two substances can be easily distinguished by IR spectra (Figure 5).

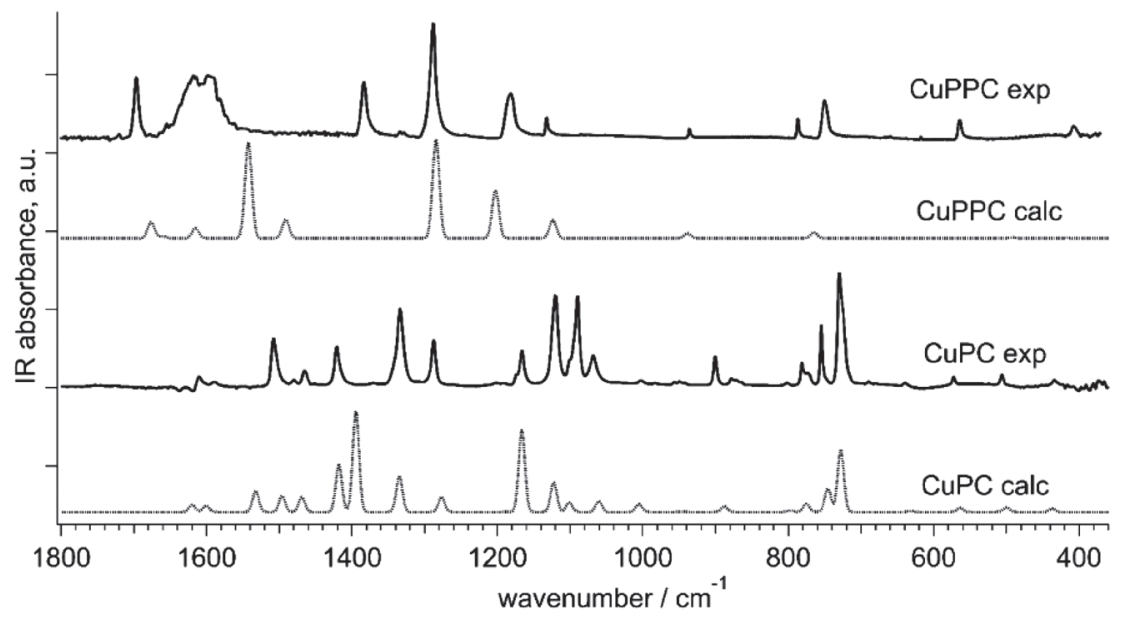

Figure 4. Comparison of infrared spectra of polymeric and monomeric phthalocyanines. Solid lines: experimental spectra (top: CuPPC, bottom: $\mathrm{CuPC}$ ), underlying dotted lines are the corresponding calculated spectra. The polymer has significantly less bands than the monomer, as expected from the structure and symmetry. Reproduced with permission from. ${ }^{[3]}$

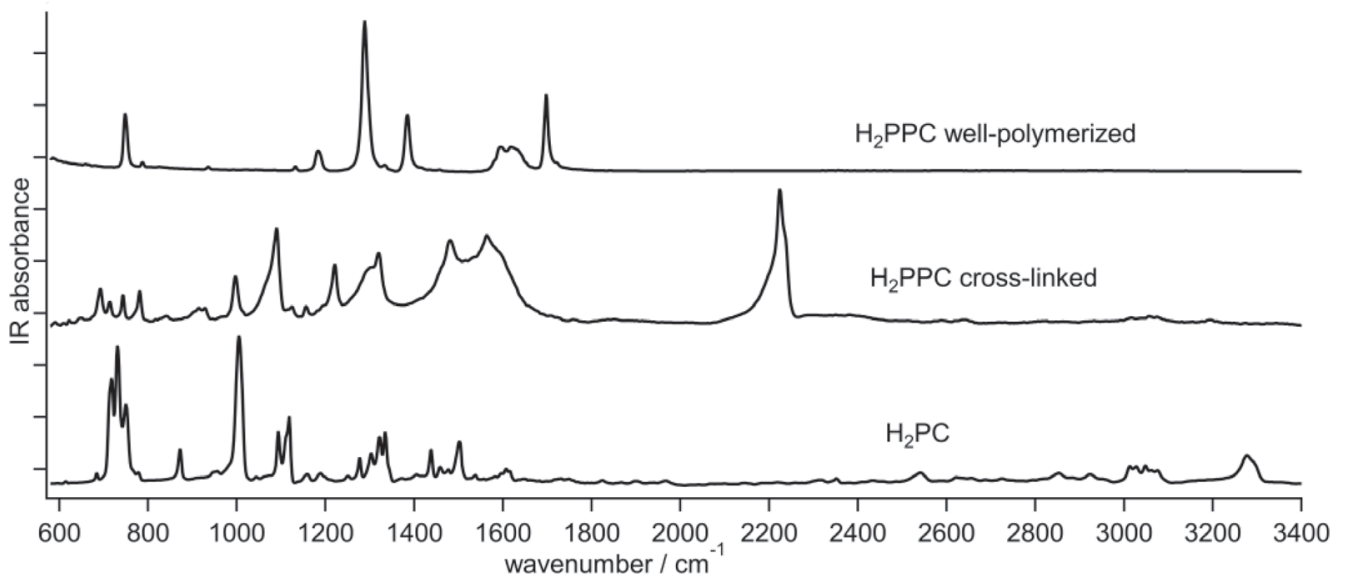

Figure 5. IR spectra of well-polymerized $\mathrm{H}_{2} \mathrm{PPC}$ (top), cross-linked product with the conjugation limited to a single PC unit (middle) and the spectrum of the "monomeric" $\mathrm{H}_{2} \mathrm{PC}$ (bottom). The cross-linked product has a high signal from the terminal groups $(-\mathrm{C} \equiv \mathrm{N})$ at $\sim 2220 \mathrm{~cm}^{-1}$, and the fingerprint region bands are close to those of the monomer, while the ordered polymer has fewer bands with negligible signal from $-\mathrm{C} \equiv \mathrm{N}$ groups. Reproduced with permission from ${ }^{[11]}$ 


\subsection{Raman spectra}

Raman spectra of PPCs are influenced by the resonance effects. Because of this, the spectra of PPCs are significantly different from those of the monomeric PCs (Figure 6). In addition, Raman cross-section depends on the electronic properties of the structural fragments, therefore in heterogeneous material the bigger-size (more conjugated) molecules give higher impact to the spectral intensity. Due to this non-linear behaviour, Raman spectroscopy gives different information as compared to IR spectra. In particular, the spectra of well-polymerized PPCs are close to those of low polymerization degree (Figure 6). DFT calculations confirm that the well-polymerized PPCs should give several intense close-lying bands in higher fingerprint region. ${ }^{[3]}$

Figure 6 shows Raman spectra of $\mathrm{H}_{2} \mathrm{PPC}$ from liquid/solid and vapor/solid reaction modes as compared to the spectra of the monomeric $\mathrm{H}_{2} \mathrm{PC}$. The other studied MePPCs $(\mathrm{Me}=\mathrm{Cr}, \mathrm{Cu}, \mathrm{Fe}, \mathrm{Co}, \mathrm{Ni})$ show analogous spectral patterns. In the fingerprint region, the bands in MePC spectra belong to the vibrations of organic skeleton of the molecule, therefore show only minor difference upon changing the central ion. ${ }^{[33]}$

\subsection{Optical absorption spectra}

UV-Vis absorption probes electronics structure of the substance, which strongly depends on the scale of electronic conjugation, or, in other words, on the polymerization degree.

In monomeric PCs, the electronic conjugation spreads mainly over the $18 \pi$-electrons of the inner ring, ${ }^{[34]}$ and the characteristic signature of such structure is the $Q$-band in 650-700 nm range, attributed to the HOMO-LUMO transition. Electronic structure of the polymeric PCs however is drastically different: depending on the central metal they either are semi-metals or have a low band gap in IR spectral region. ${ }^{[10 \mathrm{a}]}$ Therefore, the $Q$-band in visible region should not be observed in polymers. The spectrum of well-polymerized PC should be analogous to that of another 2D conjugated $\pi$-system, graphene, i.e. have continuous absorption throughout the optical region. ${ }^{[10 a, 17]}$

Quantum-chemical calculations confirm this statement. Both HOCO and LUCO of MePPCs belong to the conjugated $\pi$-electronic system (Figure 7); the energy difference between them is $0.02 \mathrm{eV}$ as compared to $\sim 1.9 \mathrm{eV}$ for $\mathrm{CuPPC}$.

The UV-Vis absorption spectra of PPCs have been discussed in several works. ${ }^{[1,10 \mathrm{~b}, 15 \mathrm{~b}-\mathrm{d}, 35]}$ Typically, the material

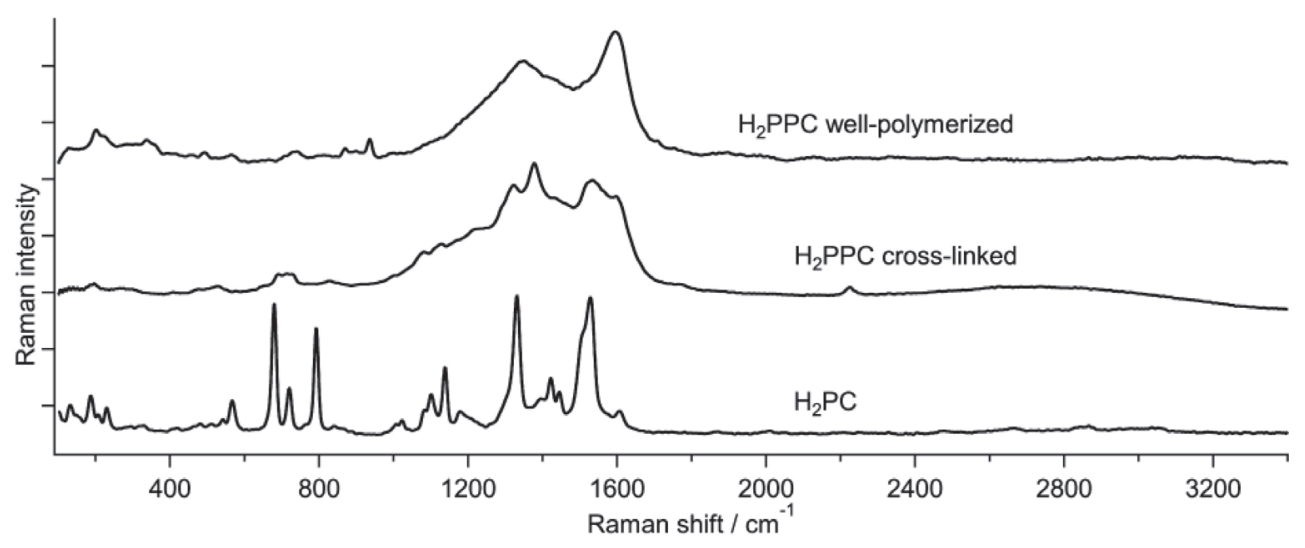

Figure 6. Raman spectra of well-polymerized $\mathrm{H}_{2} \mathrm{PPC}$ from the synthesis at vapor/solid interface (top), cross-linked product from the liquid/solid interface (middle) and the spectrum of the "monomeric" $\mathrm{H}_{2} \mathrm{PC}$ (bottom). The ordered polymer shows broad intense signal from the conjugated system of $\mathrm{CC}$ and $\mathrm{CN}$ double bonds,${ }^{[3]}$ while the spectrum of the cross-linked product is closer to that of the monomer. Reproduced with permission from. ${ }^{[11]}$
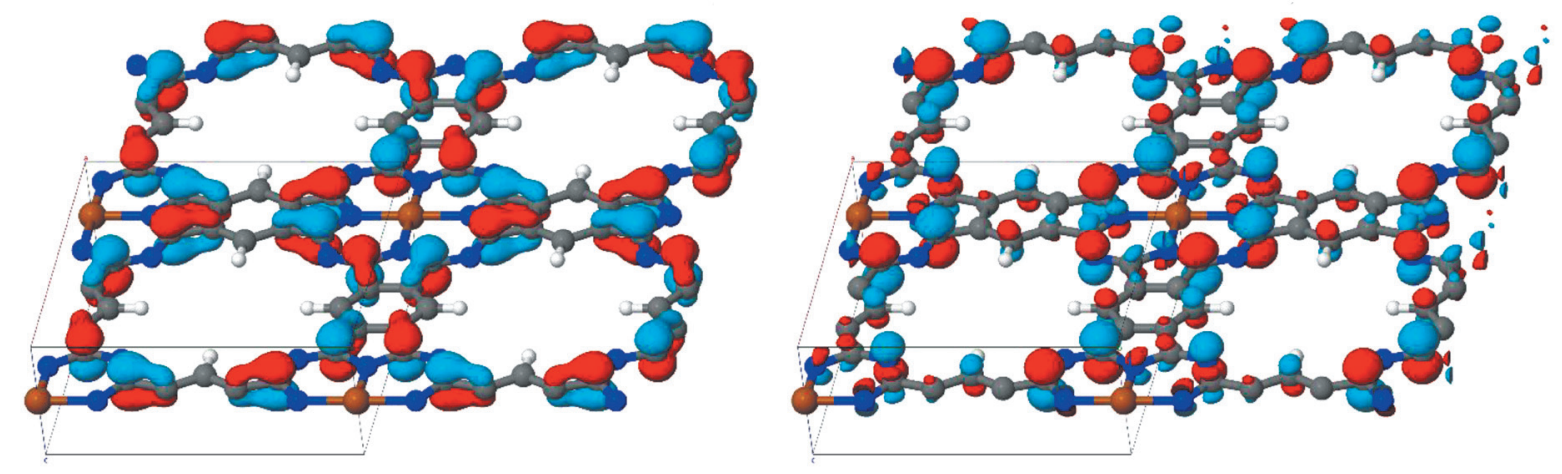

Figure 7. Frontier orbitals of PPCs belong to de-localized conjugated $\pi$-electrons (left: HOCO, right: LUCO). The calculated energy difference between these two orbitals is $0.02 \mathrm{eV}$, which is much less than that of monomeric PCs $(\sim 1.9 \mathrm{eV})$. Reproduced with permission from. ${ }^{[3]}$ 


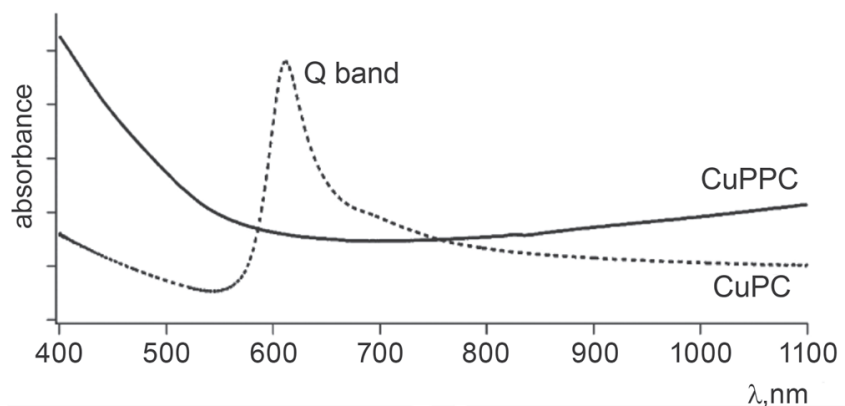

Figure 8. Comparison of UV-Vis absorption spectra of polymeric and monomeric phthalocyanines in thin films on fused silica. Solid line: $\mathrm{CuPPC}$, dotted line: CuPC. Reproduced with permission from. ${ }^{[3]}$

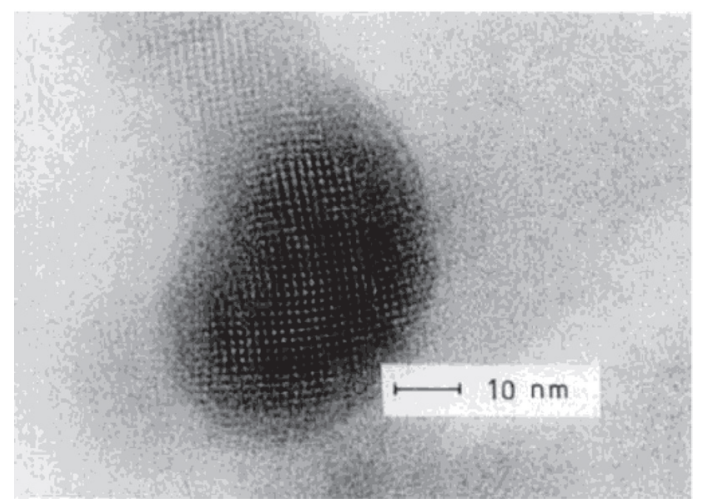

Figure 9. Molecular image of free-standing film of CuPPC. Reproduced with permission from. ${ }^{[15 b]}$

was dissolved for the measurements. It was shown that concentrated sulfuric acid can dissolve some portion of the polymer due to protonation. ${ }^{[1]}$ Nevertheless, the material of high polymerization degree was found to be insoluble even in this solvent ${ }^{[10 \mathrm{a}]}$ showing thus the behavior similar to graphene. The alleged solubility of CoPPC in dimethyl sulfoxide (DMSO) and $N$-methylpyrrolidone $(\mathrm{NMP})^{[4]}$ is a clear indication of low molecular weight. The correct comparison of the absorption spectra of monomeric and polymeric phthalocyanines should be done within the same aggregation state. Figure 8 shows optical absorption of thin films of CuPPC and $\mathrm{CuPC}$ in the visible range. As expected, the $Q$-band is observed only in the spectrum of the monomer.

\subsection{TEM}

Transmission electron microscopy (TEM) provides an important information on the degree of crystallinity, and therefore the polymerization degree. ${ }^{[11,32]}$ TEM was the first technique that visualized the square 2D lattice of PPCs ${ }^{[15 b]}$ (Figure 9).

Recently it was found that for the well-ordered CVDsynthesized PPCs the characteristic crystallite size is about few tens of $\mathrm{nm}$, while the material with the conjugation limited to single PC unit has amorphous structure (Figure 10).

\subsection{Other characterization techniques}

In early works, it was found that X-ray diffraction gives very limited information. Most likely, this is an indication of the low polymerization degree and therefore amorphous structure: only broad diffuse peaks were observed. ${ }^{[14 b]}$ After advanced approaches were developed by Wöhrle and co-workers, it became possible to record reliable XRD data. In particular, in the work ${ }^{[20]} \mathrm{CuPPC}$ was studied, and the diffraction pattern was interpreted as that of a layered compound with the inter-layer distance of $3.28 \AA$. A strong signal from $10.55 \AA$ was observed, which corresponds to metal-metal distance in the square lattice (Figure 1). Authors admit however that fitting of the experimental data with the parameters of the model lattice was far from perfect. Later, XRD was reported for thin film of CuPPC, ${ }^{[10 a]}$ and the data were compared with quantum-chemical calculations. The agreement between calculated and experimental diffraction pattern was also not complete. Well-polymerized PPC samples became available only recently, therefore to obtain new experimental data and perform a consistent interpretation is still unsolved problem. Most interesting is the stacking mode of PPC layers, which can be different, at least for monomeric PCs. ${ }^{[36]}$

Abel and co-workers studied flakes of single-layer FePPC by scanning tunneling microscopy. ${ }^{[26]}$ This was a very
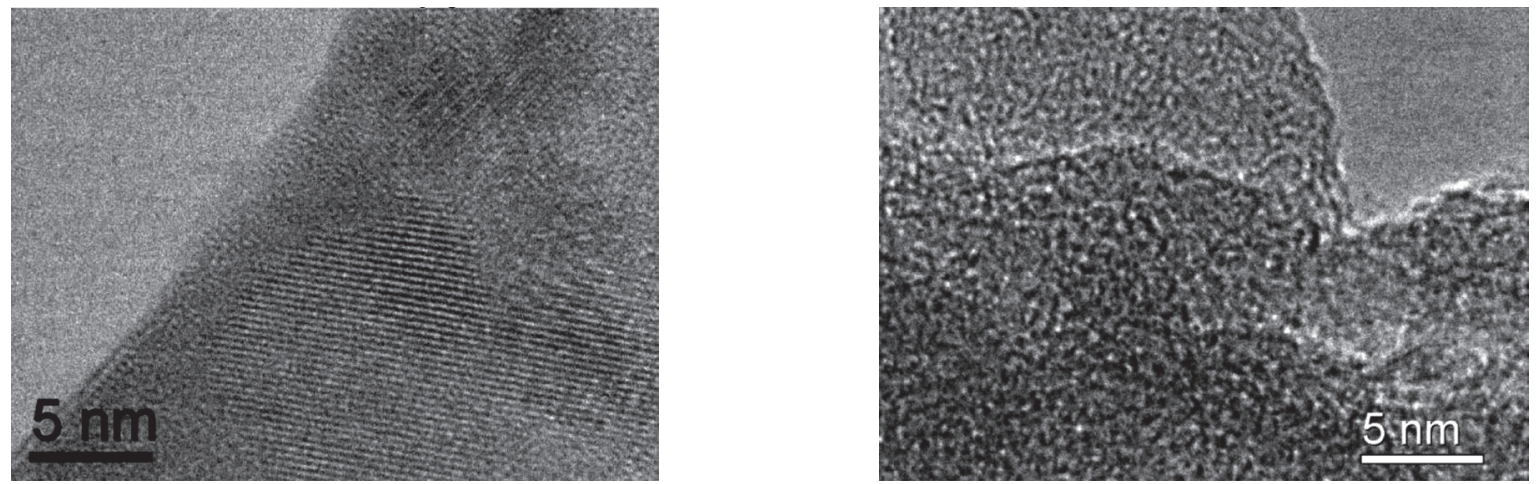

Figure 10. TEM images of ordered (left) and cross-linked (right) $\mathrm{H}_{2} \mathrm{PPC}$ materials. The characteristic crystallite size of the ordered polymer is few tens of $\mathrm{nm}$, while the cross-linked product has amorphous structure. Reproduced with permission from. ${ }^{[1]}$ 

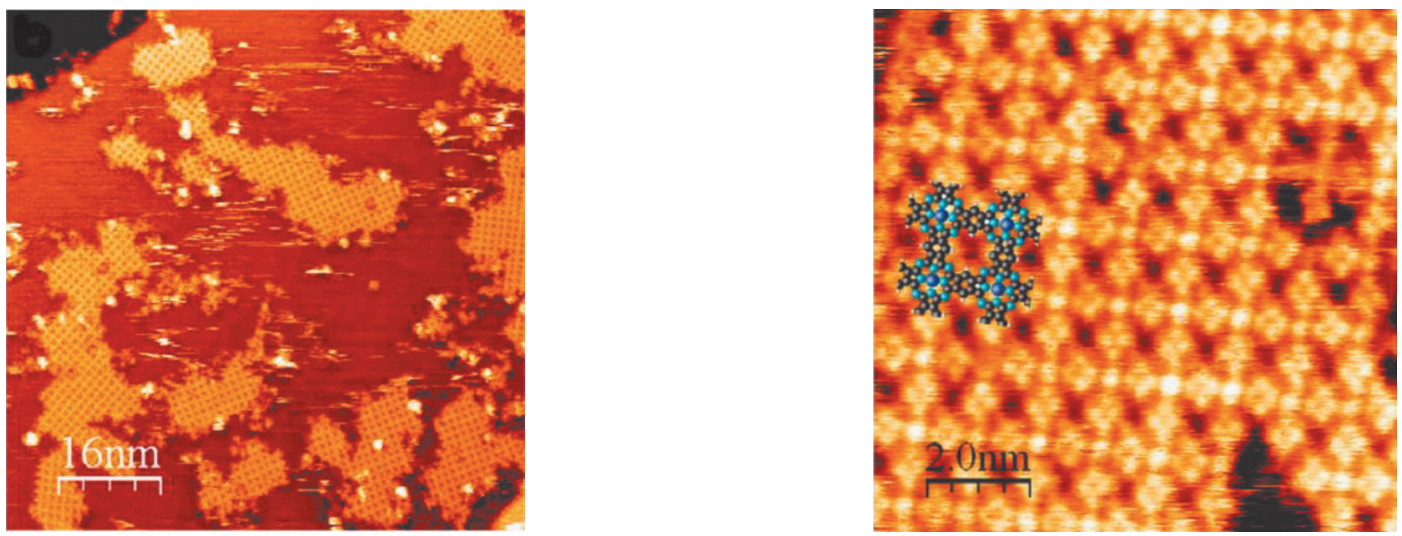

Figure 11. STM images of FePPC formed on a $\mathrm{Ag}(111)$ surface. Adapted with permission from. ${ }^{[26]}$

convincing and beautiful visualization of the $2 \mathrm{D}$ chemical structure of PPCs (Figure 11).

XPS data are available in the literature for both cross-linked (single-core) $)^{[4 a]}$ and well-polymerized ${ }^{[5]}$ PPCs. Thermogravimetric analyses (TGA) was used to study the thermal stability of PPC s $^{[37]}$ It was found in particular that polymeric PCs are less stable towards oxidative degradation than monomeric ones, ${ }^{[37 b]}$ but, since that studied product probably had low degree of uniformity, this conclusion yet has to be verified.

\subsection{Summary on characterization techniques}

Infrared spectroscopy is highly informative technique for characterization of PPCs. It gives information on the degree of uniformity and terminal groups of the polymer and allows to distinguish between single-core cross-linked PCs and well-ordered polymer. What infrared spectroscopy does not give is the stacking mode of the layers. The intense bands in the fingerprint region belong to intra-layer vibrations which behave as those of molecular crystals (i.e. inter-layer interaction is negligible compared to phonons within a single layer). XRD can access the information on the stacking mode, but reliable studies of the well-ordered polymers are yet to be done.

Resonance effects make Raman spectroscopy less useful than IR. UV-Vis absorption shows that wellpolymerized PPCs have extended electronic conjugation and are significantly different from the monomeric PCs. The distinct $Q$-band (HOMO-LUMO transition) is an indication of a low polymerization degree.

Interesting un-solved questions are spin-related properties of PPCs.

\section{Applications of PPCs}

\subsection{Catalysis}

It is known that the catalytic activity of polymeric phthalocyanines of some metals is higher than that of the corresponding monomeric PCs. ${ }^{[31]}$ Acres and Eley ${ }^{[38]}$ reported that CuPPC as well as CuPC are active catalysts for hydrogen reactions. Volumetric and the kinetic data on the $\mathrm{H}_{2}$ absorp- tion by CuPPC indicated that the absorbed hydrogen atoms are attached to copper atoms. Inoue et al. used $\mathrm{CuFePPC}$ for catalytic oxidation of acetaldehyde ethylene acetal. ${ }^{[39]}$ The degree of the $\pi$-electron conjugation in the polymer has been found to affect the catalytic activity. Hara and co-workers studied the oxidation of cumene and acrolein in the presence of CuPPC and FePPC. ${ }^{[40]}$ In the work ${ }^{[41]}$ oxidative dehydrogenation of methanol, ethanol, isopropanol and arylalcohol was studied on various metal PPCs. It was concluded that the process proceeds through the hydrogen abstraction mechanism by the activated oxygen on the central metal ion of the polymer. Later, Ohkatsu et al. ${ }^{[42]}$ confirmed this mechanism for the case of the liquid-phase oxidation. It was concluded that PPCs activate the oxygen molecule on their central metals and then abstract $\mathrm{H}_{2}$ atom from aldehydes to initiate autoxidation. To examine the $\mathrm{O}_{2}$ reduction activity, FePPC was deposited on microporous graphite supports. ${ }^{[43]}$

A new wave of PPC catalysis investigation started last decade together with increasing research interest in the field of alternative energy. The key process of many energy devices is the oxygen reduction reaction.

In $2016^{[8]}$ Zhang et al. suggested the carbonization of FeCoPPC to prepare a catalyst for methanol fuel cell. Catalyst based on the bimetal (Fe and Co) $N$-doped carbon was directly obtained from PPC through the high-temperature annealing under an Ar atmosphere. The resultant material was demonstrated to be an efficient electrocatalyst with a high $\mathrm{O}_{2}$ reduction reaction activity and good methanol tolerance. These advantages can be attributed to the synergetic effect from the Fe and Co co-doping of the $N$-doped carbon. At the same time Zhang's group ${ }^{[44]}$ obtained electrocatalyst for water splitting through the pyrolysis of crosslinked nickel-iron PPC. The water splitting device based on the same electrocatalyst at both sides of anode and cathode operated at the low cell voltage $\left(1.81 \mathrm{~V}\right.$ at $\left.10 \mathrm{~mA} / \mathrm{cm}^{2}\right)$ in $1 \mathrm{M}$ $\mathrm{KOH}$ aqueous electrolyte, as well as exhibited excellent durability (over $15 \mathrm{~h}$ of operation at $8-20 \mathrm{~mA} / \mathrm{cm}^{2}$ ) and high reversibility. Therefore, pyrolyzed PPC can be the promising material for substitution of the precious metals into water splitting catalysis.

Different carbon (carbon nanotubes (CNTs), carbon black, graphene) supports for PPC are also a developing trend in the energy devices catalysis. Recently a series 
of novel organic-carbon FePPC/CNT hybrids were developed. ${ }^{[16]}$ For this purpose, FePPC synthesis was carried out in the presence of pre-oxidized CNT in pentanol under microwave irradiation. Such hybrid electrocatalyst had a good cycling stability, apparently arising from the surface electron transfer between the carbon network and polymer structure, which largely suppressed the de-metallization of FePPC.

$\mathrm{Xu}$ et al..$^{[27]}$ have used Vulcan XC 72 (high surface area carbon powder) as support for cobalt polyphthalocyanine to prepare methanol fuel cell catalyst. CoPPC/C catalyst exhibits almost no performance degradation over continuous cyclic voltammetry at 10000 cycles, as well as significant electrocatalytic performance for $\mathrm{O}_{2}$ reduction and tolerance towards methanol. It was concluded that the active sites of catalysts are composed of $\mathrm{Co}-\mathrm{N}_{4}$ assembly in the phthalocyanine ring. Later, the same group of authors ${ }^{[28]}$ dispersed FePPC on carbon black with following heating under argon to use as cathode electrocatalyst for magnesium air fuel cells. FePPC/C polymer material had better discharge characteristics than $\mathrm{FePC} / \mathrm{C}$ monomer one. FePPC/C composite catalyzed $\mathrm{O}_{2}$ reduction mainly through a four-electron process. Magnesium air fuel cells with such hybrid catalyst can uninterruptedly function for more than 11 hours with a decrease in cell voltage of less than $0.01 \mathrm{~V}$. FePPC/C have catalytic activity close to common $\mathrm{Pt} / \mathrm{C}$ catalyst.

Lin et al. ${ }^{[45]}$ confirmed that $\mathrm{PPC} /$ carbon support catalyst possesses an excellent catalytic performance towards $\mathrm{O}_{2}$ reduction reaction comparable with the commercial $\mathrm{Pt} / \mathrm{C}$ catalyst. In their work a composite consisting of FePPC and poly(sodium- $p$-styrenesulfonate) modified graphene (PSS-Gr) was used. Hybrid catalyst was fabricated by a solvothermally assisted $\pi-\pi$ assembling method and exhibited high catalytic activity. Compared with the $\mathrm{Pt} / \mathrm{C}$ catalyst, the FePPc/PSS-Gr one possesses a good selectivity, stability and reduced methanol crossover effect.

Han et al. ${ }^{[29]}$ have prepared an organic-inorganic hybrid material by polymerization of CoPPC on CNT for a selective $\mathrm{CO}_{2}$ reduction reaction. Polymer coating on the conductive $1 \mathrm{D}$ carbon structure not only inhibits the aggregation of organic molecules and enhances their electrochemically active surface area but also enhances their physical and chemical durability.

Conjugated CoPPC was used as the cathode catalyst for flexible Li- $\mathrm{CO}_{2}$ batteries. ${ }^{[4 a]}$ Due to the cross-linked network, polymer possesses elasticity and improved physico-chemical stability and mechanical durability. CoPPC involved in the reversible electrochemical formation-decomposition of $\mathrm{Li}_{2} \mathrm{CO}_{3}$ providing small voltage polarization in $\mathrm{Li}-\mathrm{CO}_{2}$ batteries, as well as large areal capacity $\left(13.6 \mathrm{~mA} / \mathrm{cm}^{2}\right)$, as well as impressive cycling ( $>50$ cycles) and rate (up to $0.25 \mathrm{~mA} / \mathrm{cm}^{2}$ ) performances.

\subsection{Sensors}

PPCs are promising materials for sensor applications, as it was demonstrated in work: ${ }^{[46]}$ polymer conductivity was changed when PPC of aluminium and fluorine was exposed to oxidizing gases $\left(\mathrm{O}_{2}, \mathrm{NO}_{2}\right.$ and $\left.\mathrm{Cl}_{2}\right)$. Anisimov and co-workers studied the sensitivity of PPCs of zinc, copper, manganese, iron, and lead to various gases (nitrogen dioxide, ammonia, hydrogen sulfide, oxygen) ${ }^{[47]}$ It was found that CuPPC possesses a high sensitivity to $\mathrm{NO}_{2}$ and $\mathrm{H}_{2} \mathrm{~S}$ micro concentrations; $\mathrm{MnPPC}$ can be used as sensitive material for $\mathrm{O}_{2}$ concentration change detection; the electrical resistances of FePPC and PbPPC change under $\mathrm{NO}_{2}$ and $\mathrm{H}_{2} \mathrm{~S}$ exposure; FePPC demonstrates reversible signal change to $\mathrm{NH}_{3}$ presence (in range 0-100 ppm). More recently, bioactivity of $\mathrm{CuPPC}$ was also reported ${ }^{[48]} \mathrm{CuPPC}$ was combined with graphitic carbon nitride to fabricate composite electrode for determination of ractopamine using photoelectrochemical method. Copper PPC improved the photocurrent efficiency of the graphitic $\mathrm{C}_{3} \mathrm{~N}_{4}$ nanoparticles due to formation of the heterojunction, enhancing the photoelectrochemical activity of both graphitic $\mathrm{C}_{3} \mathrm{~N}_{4}$ and CuPPCs.

\subsection{Spintronics}

PPCs are promising candidates for potential applications in spintronics and future magnetic storage devices. ${ }^{[6-7,49]}$ Cho et al. ${ }^{[49]}$ theoretically demonstrated that the chromium porphyrin network possesses a half-metallic behavior when the $\mathrm{Cr}$ atom spins lie in a parallel alignment. Since the $\mathrm{Cr}$ atoms are separated by a large distance $(>8 \AA)$, the spin coupling is small and thus their directions can be simply controlled by an external magnetic field. Zhou and co-authors calculated the electronic and magnetic properties of metal (from $\mathrm{Cr}$ to $\mathrm{Zn}$ ) PPCs as free-standing sheets using density functional theory. ${ }^{[7]}$ It was found that only the MnPPC framework is ferromagnetic, while $\mathrm{CrPPC}, \mathrm{FePPC}, \mathrm{CoPPC}$ and $\mathrm{CuPPC}$ are antiferromagnetic and NiPPC, and ZnPPC are nonmagnetic. The difference in magnetic couplings for the studied systems was related to the different orbital interactions. Wang and co-workers calculated magnetic properties of a series of MePPCs ${ }^{[6]}$ with 5d-transition metals. They demonstrated that PPCs are suitable materials for the development of magnetic storage devices. Giant perpendicular magnetic anisotropy with energy of up to $20.7 \mathrm{meV}$ was found in RePPC.

\subsection{Gas separation membranes}

Recently Meng et al..$^{[50]}$ have proposed an approach to synthesize the halogenated $\mathrm{H}_{2} \mathrm{PPC}$, proposing as promising membranes for gas separation. The main characteristics of gas separation membrane are permeance and selectivity. The permeance was estimated using gas kinetic theory under ideal gas approximation. The selectivity of two gas species was calculated from the ratio of permeances or from the ratio of the diffusion rates. It was found that halogenated $\mathrm{H}_{2} \mathrm{PPC}$ monolayers can be multifunctional gas separation membranes, i.e. $\mathrm{F}-\mathrm{H}_{2} \mathrm{PPC}$ for $\mathrm{H}_{2} / \mathrm{CO}, \mathrm{H}_{2} / \mathrm{CH}_{4}, \mathrm{CO}_{2} / \mathrm{N}_{2}$, $\mathrm{CO}_{2} / \mathrm{CH}_{4}, \mathrm{CO} / \mathrm{CH}_{4}, \mathrm{~N}_{2} / \mathrm{CH}_{4}$ separation as well as $\mathrm{Cl}_{2} \mathrm{H}_{2} \mathrm{PPC}$ for $\mathrm{H}_{2} / \mathrm{CO}, \mathrm{H}_{2} / \mathrm{CH}_{4}, \mathrm{H}_{2} / \mathrm{CO}_{2}$ separation.

\subsection{Memristors}

Guo et al. ${ }^{[5]}$ were the first who produced the nonvolatile memory devices based on CVD-grown CuPPC thin films. $\mathrm{Au} / \mathrm{CuPPC} / \mathrm{ITO}$ structure exhibited good nonvolatile memory performance with a large ON/OFF current ratio of $10^{3}$ 
and long retention time of $1.2 \cdot 10^{3} \mathrm{~s}$. In the "set" process conductive filament was formed by $\mathrm{Cu}$ atoms which arise at the $\mathrm{CuPPc} / \mathrm{ITO}$ interface from reduced $\mathrm{Cu}^{2+}$ ions located at the phthalocyanine ring. In the "reset" process, the $\mathrm{Cu}$ atoms were oxidized into $\mathrm{Cu}^{2+}$ ions together with filament breaking.

\subsection{Summary on applications}

PPCs possess a number of unique properties which make these polymers highly promising materials for a variety of applications. At the moment, PPCs are actively studied as catalysts, especially for oxygen reduction reactions. Recently the composite PPC/nano-carbon were developed. It should be especially emphasized the resurgence of interest in the PPC as promising material for advanced fuel cells, water splitting devices and next generation batteries. Since metal atoms in PPC are quasi-isolated from each other, they are a potential base for spintronics and magnetic storage devices.

\section{Conclusions}

Despite a long history of 2D PPCs, the chemical structure of these materials was until recent a subject of intense debates. ${ }^{[3,51]}$ Only after quantum-chemical interpretation of the spectra became available, the reliable identification of the reaction products was established. ${ }^{[3]}$ Recent development of the CVD synthesis made possible the deposition of thin PPC films with high polymerization degree. ${ }^{[10 a, 11]}$ A progress in the long-lasting challenge of the processability of PPCs has also been achieved. The CVD approach allows selective deposition of thin films of PPCs on dielectric substrates, ${ }^{[10 a, 11]}$ nanometer-size flakes of monolayer PPCs have also been reported, ${ }^{[22,26]}$ but waferscale production of single-layer polymers may still be called "just a dream".

This material was found to be a good base for advanced memristors devices. ${ }^{[5]}$ PPCs are unique catalysts, already confirmed applications of which include new generation batteries and advanced fuel cells. ${ }^{[4 a, 27-28]}$ Theoretical studies show that PPCs are highly attractive materials for spintronics, and we hope that recent advances in synthetic approaches would make possible experimental studies of their magnetic properties.

Acknowledgements. This work was supported by the Ministry of Education and Science of the Russian Federation, state task 075-00475-19-00.

\section{References}

1. Bannehr R., Meyer G., Wöhrle D. Polym. Bull. 1980, 2, 841-846.

2. Antonelli J.A. Open Access Master's Theses 1957, 1361.

3. Korepanov V.I., Sedlovets D.M. Mater. Res. Express 2019, 6, 055317.

4. a) Chen J., Zou K., Ding P., Deng J., Zha C., Hu Y., Zhao X., Wu J., Fan J., Li Y. Adv. Mater. 2019, 31, 1805484; b) Liu J.-H.,
Yang L.-M., Ganz E. ACS Sustainable Chem. Eng. 2018, 6, 15494-15502.

5. Guo X., Liu J., Cao L., Liang Q., Lei S. ACS Omega 2019, 4 , 10419-10423.

6. Wang P., Jiang X., Hu J., Huang X., Zhao J. J. Mater. Chem. C 2016, 4, 2147-2154.

7. Zhou J., Sun Q. J. Am. Chem. Soc. 2011, 133, 15113-15119.

8. Zhang Z., Dou M., Liu H., Dai L., Wang F. Small 2016, 12, 4193-4199.

9. Yang F., Cheng S., Zhang X., Ren X., Li R., Dong H., Hu W. Adv. Mater. 2018, 30, 1702415.

10. a) Sedlovets D.M., Shuvalov M.V., Vishnevskiy Y.V., Volkov V.T., Khodos I.I., Trofimov O.V., Korepanov V.I. Mater. Res. Bull. 2013, 48, 3955-3960; b) Wöhrle D. Macromol. Rapid Commun. 2001, 22, 68-97.

11. Sedlovets D.M., Volkov V.T., Khodos I.I., Zotov A.V., Korepanov V.I. J. Phys. D: Appl. Phys. 2019, 52, 245303.

12. Marvel C., Rassweiler J.H. J. Am. Chem. Soc. 1958, 80, 1197-1199.

13. Sakamoto J., van Heijst J., Lukin O., Schlüter D. Angew. Chem. Int. Ed. 2009, 48, 1030-1069.

14. a) Epstein A., Wildi B.S. J. Chem. Phys. 1960, 32, 324-329; b) Drinkard W.C., Bailar Jr. J.C. J. Am. Chem. Soc. 1959, 81, 4795-4797.

15. a) Wöhrle D., Meyer G., Wahl B. Die Makromolekulare Chemie: Macromol. Chem. Phys. 1980, 181, 2127-2135; b) Wöhrle D., Schmidt V., Schumann B., Yamada A., Shigehara K. Ber. Bunsen-Ges. Phys. Chem. 1987, 91, 975981; c) Wöhrle D., Hündorf U. Die Makromolekulare Chemie: Macromol. Chem. Phys. 1985, 186, 2177-2187; d) Wöhrle D., Marose U., Knoop R. Die Makromolekulare Chemie 1985, 186, 2209-2228.

16. Wang X., Wang B., Zhong J., Zhao F., Han N., Huang W., Zeng M., Fan J., Li Y. Nano Res. 2016, 9, 1497-1506.

17. Sedlovets D.M., Shuvalov M.V., Khodos I.I., Trofimov O.V., Korepanov V.I. Mat. Res. Express 2018, 5, 026401.

18. Boston D.R., Bailar Jr J.C. Inorg. Chem. 1972, 11, 1578-1583.

19. Wöhrle D., Benters R., Suvorova O., Schnurpfeil G., Trombach N., Bogdahn-Rai T. J. Porphyrins Phthalocyanines 2000, 4, 491-497.

20. Djurado D., Tadlaoui S., Hamwi A., Cousseins J. Synth. Met 1991, 42, 2595-2600.

21. Yudasaka M., Nakanishi K., Hara T., Tanaka M., Kurita S., Kawai M. Synth. Met. 1987, 19, 775-780.

22. Koudia M., Abel M. Chem. Commun. 2014, 50, 8565-8567.

23. Abe K., Ohkatsu Y., Kusano T. Die Makromolekulare Chemie 1988, 189, 761-764.

24. Osada Y., Mizumoto A. J. Appl. Phys. 1986, 59, 1776-1779.

25. Wijekoon W., Xia P., Prasad P., Garvey J. MRS Online Proceedings Library Archive 1994, 354.

26. Abel M., Clair S., Ourdjini O., Mossoyan M., Porte L. J. Am. Chem. Soc. 2011, 133, 1203-1205.

27. Xu G., Li Z., Wang S., Yu X. J. Power Sources 2010, 195, 4731-4735.

28. Li Z., Yang J., Xu G., Wang S. J. Power Sources 2013, 242, $157-165$.

29. Han N., Wang Y., Ma L., Wen J., Li J., Zheng H., Nie K., Wang X., Zhao F., Li Y. Chem 2017, 3, 652-664.

30. Wang F., Wang J., Chen Z., Liu X., Xiao L., Jiang L., Qu B., Wang S., Gong Q. Chem. Lett. 2014, 43, 1040-1042.

31. Shormanova L.P., Kojfman O.I., Beresin B.D. Polym. Sci. Ser. B 1972, 15, 910-913.

32. Sedlovets D., Korepanov V., Khodos I. J. Surf. Invest.: X-Ray, Synchrotron and Neutron Techniques 2018, 12, 1073-1076.

33. Liu Z., Zhang X., Zhang Y., Jiang J. Spectrochim. Acta Part A: Molecular and Biomolecular Spectroscopy 2007, 67, $1232-1246$. 
34. Mack J., Stillman M.J. Coord. Chem. Rev. 2001, 219, 993-1032.

35. Ortiz B., Park S.M., Doddapaneni N. J. Electrochem. Soc. 1996, 143, 1800-1805.

36. Lebedeva N.Sh., Mal'kova E.A., V'yugin A.I. Rev. J. Chem. 2012, 2, 20-50.

37. a) Achar B., Fohlen G., Parker J. J. Polym. Sci.: Polym. Chem. Ed. 1982, 20, 1785-1790; b) Shormanova L., Berezin B. Polym. Sci. USSR 1970, 12, 782-787.

38. Acres G., Eley D. Trans. Faraday Soc. 1964, 60, 11571169.

39. Inoue H., Kida Y., Imoto E. Bull. Chem. Soc. Jpn. 1967, 40, 184-190.

40. Hara T., Ohkatsu Y., Osa T. Bull. Chem. Soc. Jpn. 1975, 48, $85-89$.

41. Naito S., Tamaru K. Z. Phys. Chem. 1975, 94, 150-152.

42. Ohkatsu Y., Sekiguchi O., Osa T. Bull. Chem. Soc. Jpn. 1977, 50, 701-705.
43. Appleby A., Savy M. Electrochim. Acta 1977, 22, 1315-1323.

44. Zhang Z., Qin Y., Dou M., Ji J., Wang F. Nano Energy 2016, 30, 426-433.

45. Lin L., Li M., Jiang L., Li Y., Liu D., He X., Cui L. J. Power Sources 2014, 268, 269-278.

46. Passard M., Maleysson C., Pauly A., Dogo S., Germain J.-P., Blanc J.-P. Sens. Actuators B: Chemical 1994, 19, 489-492.

47. Anisimov V., Borisov A., Ivanova O., Krutovertsev S., Sherle A., Oleinik E. Adv. Sci. Technology 2006, 51, 187-190.

48. Li X., Wang S., Meng Y., Wang X., Zhang Y., Hun X. Microchim. Acta 2019, 186, 552.

49. Cho W.J., Cho Y., Min S.K., Kim W.Y., Kim K.S. J. Am. Chem. Soc. 2010, 133, 9364-9369.

50. Meng Z., Zhang Y., Shi Q., Liu Y., Du A., Lu R. Phys. Chem. Chem. Phys. 2018, 20, 18931-18937.

51. a) Chen L., Ding Y., Yang T., Wan C., Hou H. J. Mater. Chem. C 2017, 5, 8371-8375; b) Mezei G. J. Mater. Chem. C 2019, 7, 4887-4891. 